\title{
Community-driven Evaluation of E. coli Levels in Domestic-Use Underground Water Sources in Angono, Philippines
}

\author{
Hisaaki Kato, PhD, ${ }^{1}$ Seiji Maruyama, ${ }^{2}$ Gilbert J. Merino ${ }^{3}$ and Noel R. Juban, MD ${ }^{4}$ \\ ${ }^{1}$ The Institute of Scientific and Industrial Research, Osaka University, Osaka, Japan \\ ${ }^{2}$ Research Center for Knowledge Science in Cultural Heritage, Doshisha University, Kyoto, Japan \\ ${ }^{3}$ Municipal Health Office, Angono, Rizal, Philippines \\ ${ }^{4}$ Department of Clinical Epidemiology, College of Medicine, University of the Philippines Manila
}

\begin{abstract}
Objectives. The authors considered the community-based on-site water sampling-surveys case-study in Angono, Rizal, in the Republic of the Philippines. The study was designed to determine whether individual citizens within the community could successfully collaborate in order to develop a method for quantification of E. coli levels in water (especially underground water) for domestic use.
\end{abstract}

Methods. We used techniques that had been validated in Japan for on-site evaluation of E. coli. These simple techniques enabled the on-site quantification of $\mathrm{E}$. coli levels in multiple water sources, including underground water.

Results. The techniques used in Japan were successfully adopted in the Philippines, and we cooperated with regional medical technicians, scientists, and citizens, in order to develop a system where ultimately, the people in Angono can perform all the tasks related to on-site water quality evaluation. From societal and economic perspectives, we were able to reduce the traditionally high laboratory cost (including testing cost and samples transit cost) of coliform bacteria and E. coli evaluation to a lower, fixed cost level that is affordable for regional health centers and other sites.

Conclusion. The transfer of a simple inspection method technology, under the supervision of an experienced Japanese research team, allowed us to validate the E. coli on-site quantification strategy at a regional level as "cocreation of science and society". In addition, beyond technology transfer, our collaborative efforts with scientists, regional medical engineers, and citizens, led to the creation of an NGO (non-governmental organization) that serves citizens in the town of Angono with regard to water quality assessment and certification activities.

Key Words: water quality, water management, community, local people, participatory approach, underground water, Escherichia coli, coliform bacteria, Philippines

\section{INTRODUCTION}

Poster presented at the UKRI-JST-DOST Workshop on Sustainable Coastal Communities: "Working Together for Sustainable Coastal Communities: A Multi-Funder Approach to Maximize Development Impact" December 3-7, 2019, at Hennan Hotel, Boracay Island, Aklan, Philippines.

Corresponding author: Hisaaki Kato, PhD

The Institute of Scientific and Industrial Research, Osaka University

8-1 Mihogaoka, Ibaraki, Osaka, 567-0047, Japan

Email: hisaaki@sanken.osaka-u.ac.jp
On a global scale, water (the quality of drinking water, water for irrigation, or water for recreational use) is the most relevant factor to our health. ${ }^{1}$ Poor water quality leads to water-borne infections; to safeguard against this, all nations set water quality standards in order to protect the health of their citizens. These standards are implemented as part of water resource management policies. Generally, debates on water quality standards refer to the following three guidelines that were created by the World Health Organization (WHO): A) Drinking water quality guidelines, ${ }^{2}$ B) Safety guidelines for sewage and waste water from farming or hydroponics, ${ }^{3}$ and C) Guidelines for safe recreational water use. ${ }^{4}$ 
Strategies for monitoring water quality and for preventing water contamination are highly context-dependent. For example, in the Philippines, there are many sources of contamination; heavy emphasis is especially placed on monitoring drinking water for contamination with inorganic substances including the heavy metals $\mathrm{Cr}$, As, and $\mathrm{Pb}{ }^{5}$ However, many other factors contribute to regional water pollution, including the ecological conditions, geographical conditions, and the proximity of water to industrial activities or by-products. It is not appropriate to assume that there is heavy metal contamination when conducting regional water resource monitoring. For example, in the drinking water analysis $^{6}$ and bottled water analysis ${ }^{7}$ in Angono, Rizal, we failed to detect any inorganic contamination (heavy metals) based on the WHO guidelines.

Generally, materials that affect water quality are classified as either organic or inorganic matter. In many developing countries, contamination by organic matter (mainly form wastewater) due to rapid population increase is the most important factor that influences water quality and health risk. This is evidenced by various $\mathrm{WHO}$ water quality guidelines and the fact that the utmost concern of the organization is "Health risk caused by human waste" ${ }^{1}$ Furthermore, and regardless of the particular country, water quality evaluation based on "contamination by E. coli" index (which includes infectious diseases caused by human waste and other general microorganisms) remains a key challenge for water resource management. However, scientific methodology for monitoring this contamination is not easy for regional parties (local area doctors, medical technicians, and insurance people) to execute. Making such methodology easier to adopt by regional people will have profound and positive health and societal benefits.

We focused the research area of this study on Angono, Rizal, in the Republic of the Philippines (Figure 1). Here we report our principal findings from this study, which was

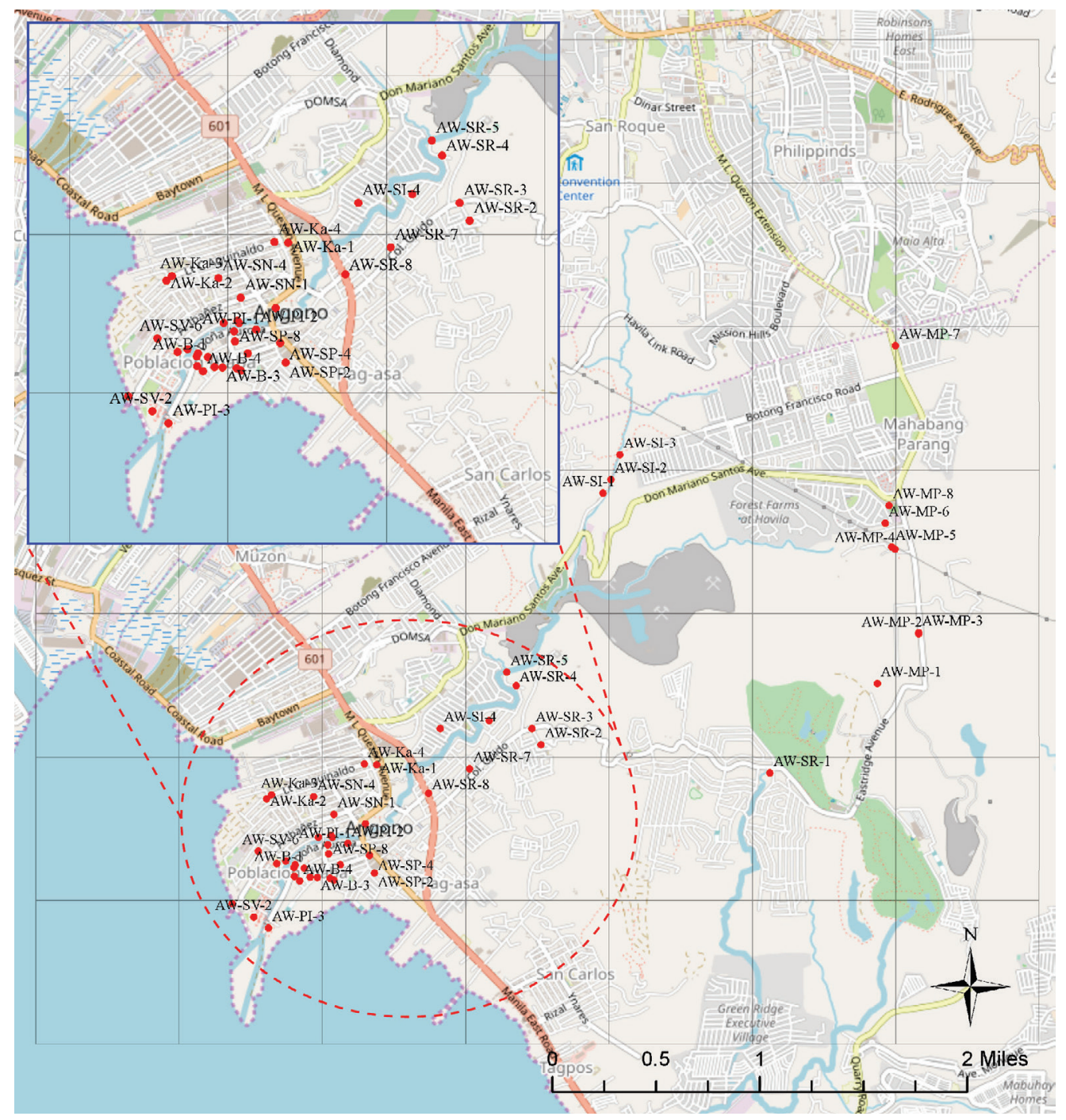

Figure 1. Map of the municipality of Angono, indicating all sampling points. 
initiated in 2014. Specifically, we introduced methods, that were already well established in Japan, for detection and quantification of E. coli. Individuals across the healthcare, science, and non-expert sectors were empowered by the adoption of these techniques, and are now in a position to carry out on-site water quality assessments autonomously.

\section{METHODS}

Our study was designed to facilitate transfer of a scientific method for quantitative evaluation of coliform bacteria and E. coli (using "EC Blue 100" and "MPN Plate"; manufactured by Nissui Pharmaceutical Co., Ltd., Japan) specifically to laboratories in the Filipino community. The final objective was to enable the local communities to proactively assess the quality of well and tap water and encourage autonomous activities to stimulate a consciousness of local water environment conservation. This objective is perfectly in line with the basic principle of public hygiene, i.e., the prevention of human health risk in local communities.

The rationale behind our decision to monitor E. coli from fecal waste in well and tap water (with which local residents most often come in contact with as drinking and domestic-use water) was based on WHO's Guidelines for
Drinking-water Quality. ${ }^{2}$ This guideline states the "value, turbidity, $\mathrm{pH}$, sterilization of fecal coliform bacteria" as an important indicator of drinking water quality, and the "preservation of groundwater sources, appropriate treatment for the water quality, and sanitary surveys as the monitoring and management tools" as requisites to create an environment that maintains public health. ${ }^{2}$ As mentioned earlier, the basic cause of water quality risk is closely related to the "fecal wastes of human beings (and, in some part, of animals)." This leads to the three-step solution of monitoring whether water is contaminated by pathogens from fecal waste, ${ }^{1}$ inactivating the pathogens using various methods, ${ }^{2}$ and control of future pathogen spread. ${ }^{3}$ Among these steps, we focused on water monitoring for contamination with pathogens from fecal waste. We considered that a "good quantitative grasp of the E. coli contamination by the local community" was essential at the beginning of the project, as this would facilitate subsequent inactivation and control of pathogens. Additionally, we determined that the use of a simplified and established scientific test method would be the ideal tool to reach the objective of solving the public hygiene challenge at the local level.

Our on-site evaluate methodology was quite simple and consisted of six elements (Figure 2): (1) $100 \mathrm{~mL}$ of sample

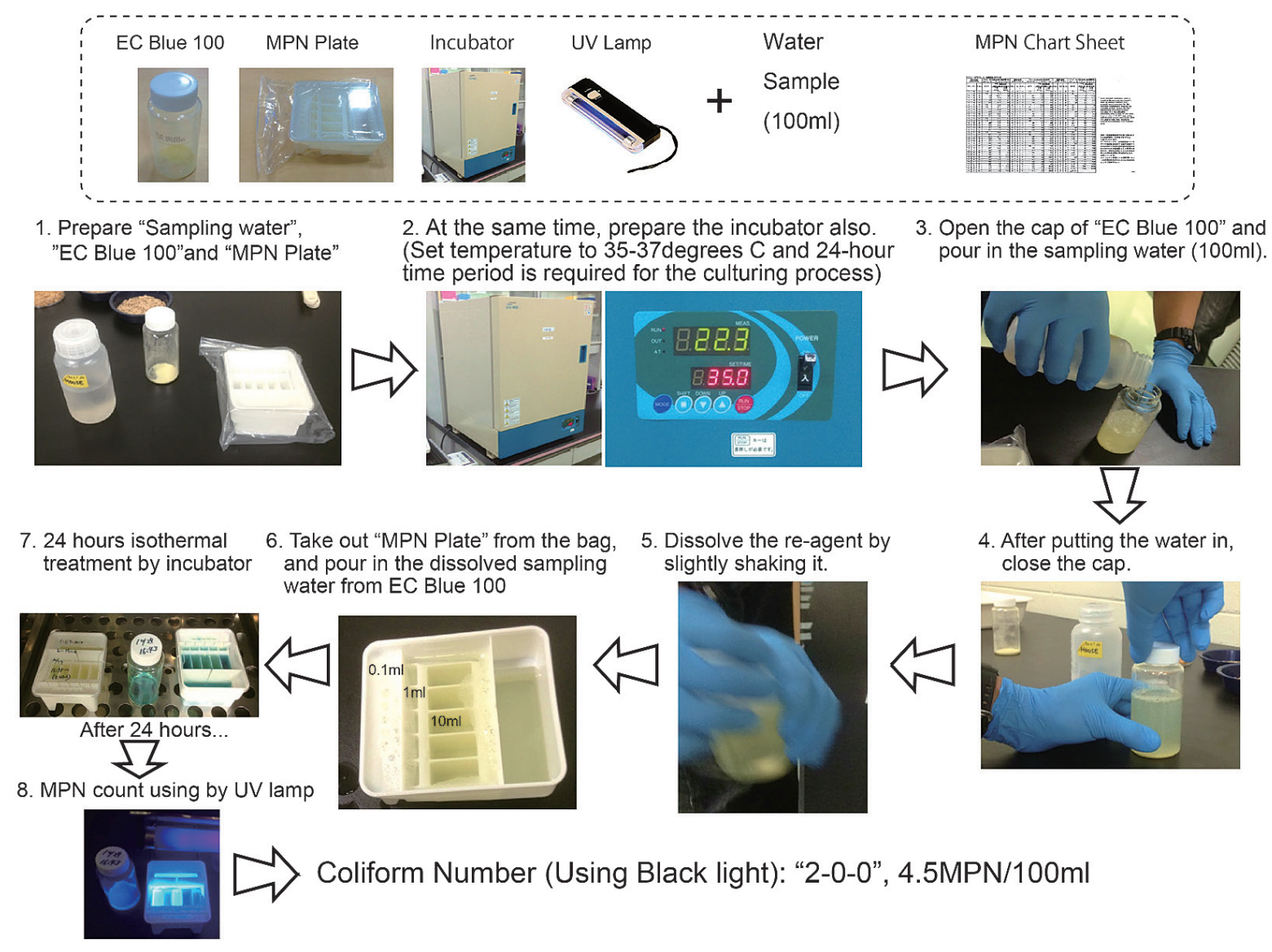

Figure 2. Testing method: EC Blue 100 \& MPN Plate. 
water, (2) EC Blue 100 (hereafter abbreviated as "EC-B") bottles containing the reagent, (3) MPN Plates (hereafter abbreviated as "MPNP") (MPN = Most Probable Number), (4) a UV light source, (5) a small incubator (24 hours at $35{ }^{\circ} \mathrm{C}$ ), and (6) low light levels; either by using a dark room, or using a cardboard box.

Given the limited resources available at the target locales, we had to find a compromise between the materials required to give scientific precision with the materials available in the local communities.

As our preceding study indicated, the simplified method for evaluation of drinking water works best when applied frequently; more complicated multi-attribute evaluation is required when resources for the tests are not regularly available. ${ }^{1}$ Also, high quality water that will meet the E. coli contamination standard is not readily available in many developing countries. If we blindly impose threshold criteria for contamination in developed countries, many of the water sources providing water for the community would be disqualified. In this situation, local communities may easily turn to even riskier water sources. We strongly believe that scientists must always take such element into consideration. In the following section, we would like to outline the study area and the methodology we used.

\section{Study Area}

This study was conducted in Angono, Rizal, Republic of the Philippines, a municipality facing Laguna de Bay (also known as Laguna Lake), one of the largest inland waters in Asia. Dr. Kato has been working on the hydrological and water quality study around Laguna de Bay in the Philippines since the end of 2012 in collaboration with the University of the Philippines Manila (UP Manila) and the University of the Philippines Los Baños (UPLB). ${ }^{8}$ By request from the University of the Philippines Manila coresearch member Dr. Noel Juban, together withlocal health authorities, he initiated efforts to transfer a simplified onsite water quality assessment technique for E. coli in 2013, and has since been building the cooperative relationship with the local authority. Back in March 19, 2014, Dr. Kato and co-researcher Dr. Kiyoyuki Yaota, accompanied by Dr. Juban, visited Angono Mayor Gerardo V. Calderon for discussion to start the collaborative work on water sampling analysis and on-site evaluation. The work was referred to Dr. Jose A. Lozo (Municipal Health Officer) and to Gilbert J. Merino (Medical Technologist) of the Municipal Health Office for local assistance.

Angono is located approximately $30 \mathrm{~km}$ from Manila. There are several urban areas, including Metro Manila, around the municipality, and on its southwest edge sits the well-known catchment of Laguna de Bay. Covering an area of $1,282 \mathrm{ha}$. the municipality has approximately 74,000 residents and consists of nine barangays (or villages). ${ }^{8}$ Angono is often affected by floods due to the rise in water level of Laguna de Bay during typhoons. ${ }^{8}$ While the lake is a huge catchment, its outflow is very limited. ${ }^{8}$ Therefore, the change in water level due to typhoons and other factors often leads to serious overflow and flood damage to the surroundings, which frequently affect the sewage treatment of wells and septic tanks and heighten health risks posed by coliform bacteria. ${ }^{8}$

As prevention of flood damage due to frequent typhoons on a year-by-year basis is unfeasible, we were convinced that transfer of a scientific technique to monitor the fecal contamination of domestic-use water to the local communities would be possible. In pursuit of the solution to public hygiene challenges in light of the ever-changing water environment, we realized that local communities would request simple but effective countermeasures that the municipality of Angono could implement at its own discretion. The water quality assessment system transferred under this philosophy was spread throughout the area by efforts of our co-researcher, Merino. An NGO (Angono Safe Water Association) has now been established in the area, and the initiative is ongoing at the time of writing.

\section{Simplified Examination Technique}

We used two apparatuses to evaluate E. coli contamination: the EC-B and the MPNP. Dr. Kato developed the original English user's manual, which was included in the booklet he later published for the concerned parties of the municipality of Angono. ${ }^{8}$

The first apparatus, EC-B (Figure 2), is a bottle that enables the qualitative evaluation of $\mathrm{E}$. coli in water. It is essentially a cultivation bottle containing the reagent to cultivate microbes. The bottle is kept with $100 \mathrm{~mL}$ of the sample water in the incubator for $24 \mathrm{~h}$ at a constant temperature of $35^{\circ} \mathrm{C}$. The change in color will indicate the presence or absence of coliform bacteria. The EC-B bottle is quite easy to handle and keeps for approximately two years at room temperature (around $30{ }^{\circ} \mathrm{C}$ ) and thus can be stored at health centers. The bottles must be kept away from direct sunlight. Moreover, especially in Southeast Asian countries, the bottles definitely need to be protected from moisture, because the reagent is hygroscopic. However, EC-B can only be used for the qualitative evaluation of $\mathrm{E}$. coli in sample water after incubation with the enzyme in the bottle; therefore, MPNP is required for the quantitative evaluation.

The second apparatus, the MPNP (Figure 2), is a plastic plate that can be used to determine the most probable number of $\mathrm{E}$. coli in a quantitative manner, using the sample water mixed with the reagent in the EC-B. It is a disposable plate intended for single use, and thus is individually wrapped after sterilization. The MPNP should be stored at room temperature. Sample water mixed with the reagent in the EC-B bottle is dispensed into the MPNP, and kept in the incubator for $24 \mathrm{~h}$ at a constant temperature of $35^{\circ} \mathrm{C}$. The plate is then exposed to UV light in the darkroom, and the resulting fluorescence is quantified in order to evaluate the MPN of E. coli; values are expressed as the amount of E. coli present in $100 \mathrm{~mL}$ of sample water. 
Table 1. Environmental standard reference for water quality in the Philippines (E. coli)

\begin{tabular}{|c|c|c|c|}
\hline Class & $\begin{array}{l}\text { Water utilization } \\
\text { (for Rivers and Lakes) }\end{array}$ & $\begin{array}{l}\text { Total coliform } \\
\text { (MPN/100mL) }\end{array}$ & $\begin{array}{c}\text { Fecal coliform } \\
\text { bacteria } \\
\text { (MPN/100mL) }\end{array}$ \\
\hline AA & $\begin{array}{l}\text { Water supply } 1^{\text {st }} \text { level } \\
\text { (Domestic use) }\end{array}$ & 50 & 20 \\
\hline A & Water supply $2^{\text {nd }}$ level & 1,000 & 100 \\
\hline B & Recreation Water $1^{\text {st }}$ level & 1,000 & 200 \\
\hline C & $\begin{array}{l}\text { Marine Products Industry } \\
\text { Recreation Water } 2^{\text {nd }} \text { level } \\
\text { Industrial water } 1^{\text {st }} \text { level }\end{array}$ & 5,000 & - \\
\hline D & $\begin{array}{l}\text { Irrigation water } \\
\text { Industrial water } 2^{\text {nd }} \text { level } \\
\text { Fresh water for other task }\end{array}$ & - & - \\
\hline
\end{tabular}

Source: DENR Administrative Order No.34, Series of 1990; Revised Water Usage and Classification / Water Quality Criteria Amending Section Nos: 68 and 69, Chapter III of the 1978 NPCC Rules and Regulations Criteria of Water Use Regulation

These apparatuses can be used in two different ways to obtain different environmental information according to the requirements of the test operators. By using only the $\mathrm{EC}-\mathrm{B}$, the presence of $\mathrm{E}$. coli in the examined water sample can be qualitatively checked. On the other hand, the combination of the EC-B and the MPNP facilitates the quantitative determination of $\mathrm{E}$. coli.

Of note, WHO's guideline for drinking water ${ }^{2}$ states that $0 \mathrm{CFU}$ (Colony Forming Units) and 0 coliform bacteria count is allowed in $100 \mathrm{~mL}$ of water for domestic use. On the other hand, the water quality standard setting reference by Filipino DENR ${ }^{9}$ states that an MPN of 50 CFU for total coliform and $20 \mathrm{CFU}$ for fecal coliforms are allowed for Class AA (grade 1 waterworks), which deviates significantly from the WHO's guideline (see chart). However, many citizens are using not only tap water but well water source for domestic use (washing, drinking for some, among other uses) in the town of Angono. Generally, when we considered to define a criterion for measuring E. coli of well water in many countries in the world, we must assume that although much well water is used for recreation, there is also the possibility that it is also used for drinking purposes. Therefore, when we considered about well water standards in Japanese reference, we adopted the local standards of E. coli count used for tap water supply. This is the reason that we referenced the WHO and DENR's water standards information. As a result, taking the development status of the test area, we have decided to use this working definition: " $0-20 \mathrm{CFU}$ coliform per $100 \mathrm{~mL}$ of water as the threshold for classifying water quality as acceptable".

The test method using the EC-B and the MPNP is quite simple and easy to understand, and therefore the locals do not require sophisticated training programs or prior experience of the methodology (Table 2). Indeed, many medical technicians in Angono have learned the procedure during the collaboration in several field studies. The detailed procedure is provided below.
1. Prepare $100 \mathrm{~mL}$ of the sample water, and have the EC-B and MPNP ready. At the same time, activate the incubator to raise the interior temperature to the required level $\left(35-37{ }^{\circ} \mathrm{C}\right)$. Under these conditions, the level of contamination can be measured after $24 \mathrm{~h}$ of cultivation.

2. Open the cap of the EC-B bottle and add $100 \mathrm{~mL}$ of the sample water. Make sure to specify the name of the sample on the cap.

3. Close the cap and shake the EC-B bottle until the reagent is dissolved.

4. Take the MPNP out of the sterilized packet and open the lid of the EC-B bottle. Then add the water mixed with the reagent. There are three groups of slots in each MPNP, with volumes of $0.1 \mathrm{~mL}, 1 \mathrm{~mL}$, and $10 \mathrm{~mL}$; each slot is divided into five sections (Figure 2). Be sure that all extra slots are completely filled with the sample water.

5. Close the lid of the MPNP, place in the incubator, and cultivate the microbes for $24 \mathrm{~h}$, ensuring that sample names are indicated on the lid of the MPNP. All preparatory work prior to placing the plate in the incubator must be completed in less than $30 \mathrm{~min}$. Sample water mixed with the reagent must not be left at room temperature for more than $30 \mathrm{~min}$. This time limit is based on results obtained with the "defined substrate method" of Japan ${ }^{10}$ and the "inspection method" ${ }^{11}$

6. After the 24-h cultivation, take the plate out of the incubator and check the color of the sample water. If the sample water does not turn blue, there is no contamination by coliform bacteria or E. coli. For the samples with no color change, record "0 $\mathrm{CNF}$ coliform bacteria and E. coli found in $100 \mathrm{~mL}$ " and finish the evaluation. If the sample water turns blue, it is contaminated by coliform bacteria.

7. Blue samples should be evaluated following illumination with UV light at $366 \mathrm{~nm}$. This wavelength is normally identical to those of commercial black-light lamps.

8. In the darkened room, expose the sample water on the MPNP to the UV light. If contaminated by E. coli, water in the slots of " $0.1 \mathrm{~mL}$," " $1 \mathrm{~mL}$ ", or " $10 \mathrm{~mL}$ " will exhibit fluorescence. Count the number of slot(s) showing fluorescence and calculate the colony size based on the calculation sheet attached to MPNPs ${ }^{12}$ (Table 2).

9. After the evaluation, dilute the sample water with tap water and discard in the sewage. The used EC-B and MPNP should be (whenever possible) sterilized by autoclaving before being discarded. In case autoclave is not available, samples can be boiled in order to sterilize them.

Through dialogue with the local communities, we focused on the technical transfer of a simplified evaluation method and, together with the local health bureau, worked to develop the human resource to understand the current situation of well water used as domestic-use water. The quality of tap water provided by Manila Water Company Inc. 
Table 2. MPN Count Chart (Nissui Pharmaceutical Co., Ltd.)

\begin{tabular}{|c|c|c|c|c|c|c|c|c|c|c|c|}
\hline \multicolumn{3}{|c|}{ positive number } & \multicolumn{3}{|c|}{ MPN in $100 \mathrm{~mL} \&$ confidence limit } & \multicolumn{3}{|c|}{ positive number } & \multicolumn{3}{|c|}{ MPN in $100 \mathrm{~mL} \&$ confidence limit } \\
\hline \multirow{2}{*}{$10 \mathrm{~mL}$} & \multirow{2}{*}{$1 \mathrm{~mL}$} & \multirow{2}{*}{$0.1 \mathrm{~mL}$} & \multirow{2}{*}{ MPN } & \multicolumn{2}{|c|}{ 95\% confidence limit } & \multirow{2}{*}{$10 \mathrm{~mL}$} & \multirow{2}{*}{$1 \mathrm{~mL}$} & \multirow{2}{*}{$0.1 \mathrm{~mL}$} & \multirow{2}{*}{ MPN } & $95 \%$ co & Ice limit \\
\hline & & & & lower & upper & & & & & lower & upper \\
\hline 0 & 0 & 0 & 0 & & & 3 & 0 & 0 & 7.8 & 2.5 & 24 \\
\hline 0 & 0 & 1 & 1.8 & 0.23 & 14 & 3 & 0 & 1 & 11 & 3.7 & 30 \\
\hline 0 & 0 & 2 & 3.6 & 0.8 & 16 & 3 & 0 & 2 & 13 & 5 & 36 \\
\hline 0 & 0 & 3 & 5.4 & 1.5 & 20 & 3 & 0 & 3 & 16 & 6.2 & 44 \\
\hline 0 & 0 & 4 & 7.2 & 2.3 & 23 & 3 & 0 & 4 & 20 & 7.5 & 51 \\
\hline 0 & 0 & 5 & 9 & 3.1 & 27 & 3 & 0 & 5 & 23 & 8.7 & 60 \\
\hline 0 & 1 & 0 & 1.8 & 0.24 & 14 & 3 & 1 & 0 & 11 & 3.8 & 30 \\
\hline 0 & 1 & 1 & 3.6 & 0.81 & 16 & 3 & 1 & 1 & 14 & 5.1 & 37 \\
\hline 1 & 1 & 2 & 5.5 & 1.5 & 20 & 3 & 1 & 2 & 17 & 6.3 & 44 \\
\hline 0 & 1 & 3 & 7.3 & 2.3 & 23 & 3 & 1 & 3 & 20 & 7.6 & 52 \\
\hline 0 & 1 & 4 & 9.1 & 3.1 & 27 & 3 & 1 & 4 & 23 & 8.8 & 61 \\
\hline 0 & 1 & 5 & 11 & 3.9 & 31 & 3 & 1 & 5 & 27 & 10 & 72 \\
\hline 0 & 2 & 0 & 3.7 & 0.82 & 16 & 3 & 2 & 0 & 14 & 5.1 & 37 \\
\hline 0 & 2 & 1 & 5.5 & 1.5 & 20 & 3 & 2 & 1 & 17 & 6.4 & 45 \\
\hline 0 & 2 & 2 & 7.4 & 2.3 & 23 & 3 & 2 & 2 & 20 & 7.7 & 53 \\
\hline 0 & 2 & 3 & 9.2 & 3.1 & 27 & 3 & 2 & 3 & 24 & 8.9 & 62 \\
\hline 0 & 2 & 4 & 11 & 3.9 & 31 & 3 & 2 & 4 & 27 & 10 & 73 \\
\hline 0 & 2 & 5 & 13 & 4.7 & 35 & 3 & 2 & 5 & 31 & 11 & 85 \\
\hline 0 & 3 & 0 & 5.6 & 1.6 & 20 & 3 & 3 & 0 & 17 & 6.5 & 45 \\
\hline 0 & 3 & 1 & 7.4 & 2.3 & 23 & 3 & 3 & 1 & 21 & 7.8 & 54 \\
\hline 0 & 3 & 2 & 9.3 & 3.2 & 27 & 3 & 3 & 2 & 24 & 9.1 & 64 \\
\hline 0 & 3 & 3 & 11 & 4 & 31 & 3 & 3 & 3 & 28 & 10 & 74 \\
\hline 0 & 3 & 4 & 13 & 4.8 & 35 & 3 & 3 & 4 & 31 & 11 & 86 \\
\hline 0 & 3 & 5 & 15 & 5.6 & 40 & 3 & 3 & 5 & 35 & 12 & 100 \\
\hline 0 & 4 & 0 & 7.5 & 2.4 & 20 & 3 & 4 & 0 & 21 & 7.9 & 55 \\
\hline 0 & 4 & 1 & 9.4 & 3.2 & 27 & 3 & 4 & 1 & 24 & 9.2 & 65 \\
\hline 0 & 4 & 2 & 11 & 4 & 31 & 3 & 4 & 2 & 28 & 10 & 76 \\
\hline 0 & 4 & 3 & 13 & 4.8 & 36 & 3 & 4 & 3 & 32 & 12 & 88 \\
\hline 0 & 4 & 4 & 15 & 5.6 & 40 & 3 & 4 & 4 & 36 & 13 & 100 \\
\hline 0 & 4 & 5 & 17 & 6.4 & 45 & 3 & 4 & 5 & 40 & 14 & 120 \\
\hline 0 & 5 & 0 & 9.4 & 3.2 & 28 & 3 & 5 & 0 & 25 & 9.3 & 66 \\
\hline 0 & 5 & 1 & 11 & 4.1 & 32 & 3 & 5 & 1 & 29 & 11 & 77 \\
\hline 0 & 5 & 2 & 13 & 4.9 & 36 & 3 & 5 & 2 & 32 & 12 & 90 \\
\hline 0 & 5 & 3 & 15 & 5.7 & 40 & 3 & 5 & 3 & 37 & 13 & 100 \\
\hline 0 & 5 & 4 & 17 & 6.5 & 45 & 3 & 5 & 4 & 41 & 14 & 120 \\
\hline 0 & 5 & 5 & 19 & 7.2 & 50 & 3 & 5 & 5 & 45 & 15 & 140 \\
\hline 0 & 5 & 0 & 9.4 & 3.2 & 28 & 4 & 0 & 0 & 13 & 4.7 & 35 \\
\hline 0 & 5 & 1 & 11 & 4.1 & 32 & 4 & 0 & 1 & 17 & 6.3 & 44 \\
\hline 0 & 5 & 2 & 13 & 4.9 & 36 & 4 & 0 & 2 & 21 & 7.9 & 54 \\
\hline 0 & 5 & 3 & 15 & 5.7 & 40 & 4 & 0 & 3 & 25 & 9.5 & 67 \\
\hline 0 & 5 & 4 & 17 & 6.5 & 45 & 4 & 0 & 4 & 30 & 11 & 83 \\
\hline 0 & 5 & 5 & 19 & 7.2 & 50 & 4 & 0 & 5 & 36 & 12 & 100 \\
\hline 1 & 0 & 0 & 2 & 0.28 & 14 & 4 & 1 & 0 & 17 & 6.4 & 45 \\
\hline 1 & 0 & 1 & 4 & 0.94 & 17 & 4 & 1 & 1 & 21 & 8.1 & 56 \\
\hline 1 & 0 & 2 & 6 & 1.7 & 21 & 4 & 1 & 2 & 26 & 9.7 & 69 \\
\hline 1 & 0 & 3 & 8.1 & 2.6 & 25 & 4 & 1 & 3 & 31 & 11 & 85 \\
\hline 1 & 0 & 4 & 10 & 3.5 & 29 & 4 & 1 & 4 & 36 & 13 & 100 \\
\hline 1 & 0 & 5 & 12 & 4.4 & 34 & 4 & 1 & 5 & 42 & 14 & 130 \\
\hline 1 & 1 & 0 & 4 & 0.95 & 17 & 4 & 2 & 0 & 22 & 8.2 & 57 \\
\hline 1 & 1 & 1 & 6.1 & 1.8 & 21 & 4 & 2 & 1 & 26 & 9.9 & 71 \\
\hline 1 & 1 & 2 & 8.1 & 2.7 & 25 & 4 & 2 & 2 & 32 & 11 & 88 \\
\hline 1 & 1 & 3 & 10 & 3.6 & 29 & 4 & 2 & 3 & 38 & 13 & 110 \\
\hline 1 & 1 & 4 & 12 & 4.5 & 34 & 4 & 2 & 4 & 44 & 15 & 130 \\
\hline 1 & 1 & 5 & 14 & 5.4 & 39 & 4 & 2 & 5 & 50 & 16 & 160 \\
\hline 1 & 2 & 0 & 6.1 & 1.8 & 21 & 4 & 3 & 0 & 27 & 10 & 73 \\
\hline 1 & 2 & 1 & 8.2 & 2.7 & 25 & 4 & 3 & 1 & 33 & 12 & 91 \\
\hline 1 & 2 & 2 & 10 & 3.6 & 29 & 4 & 3 & 2 & 39 & 13 & 110 \\
\hline
\end{tabular}


Table 2. MPN Count Chart (Nissui Pharmaceutical Co., Ltd.) (continued)

\begin{tabular}{|c|c|c|c|c|c|}
\hline \multicolumn{3}{|c|}{ positive number } & \multicolumn{3}{|c|}{ MPN in $100 \mathrm{~mL} \&$ confidence limit } \\
\hline \multirow{2}{*}{$10 \mathrm{~mL}$} & \multirow{2}{*}{$1 \mathrm{~mL}$} & \multirow{2}{*}{$0.1 \mathrm{~mL}$} & \multirow{2}{*}{ MPN } & \multicolumn{2}{|c|}{ 95\% confidence limit } \\
\hline & & & & lower & upper \\
\hline 1 & 2 & 3 & 12 & 4.5 & 34 \\
\hline 1 & 2 & 4 & 15 & 5.4 & 39 \\
\hline 1 & 2 & 5 & 17 & 6.3 & 44 \\
\hline 1 & 3 & 0 & 8.3 & 2.7 & 25 \\
\hline 1 & 3 & 1 & 10 & 3.6 & 30 \\
\hline 1 & 3 & 2 & 13 & 4.6 & 34 \\
\hline 1 & 3 & 3 & 15 & 5.5 & 39 \\
\hline 1 & 3 & 4 & 17 & 6.4 & 44 \\
\hline 1 & 3 & 5 & 19 & 7.3 & 50 \\
\hline 1 & 4 & 0 & 11 & 3.7 & 30 \\
\hline 1 & 4 & 1 & 13 & 4.6 & 35 \\
\hline 1 & 4 & 2 & 15 & 5.6 & 40 \\
\hline 1 & 4 & 3 & 17 & 6.5 & 45 \\
\hline 1 & 4 & 4 & 19 & 7.3 & 51 \\
\hline 1 & 4 & 5 & 22 & 8.2 & 56 \\
\hline 1 & 5 & 0 & 13 & 4.7 & 35 \\
\hline 1 & 5 & 1 & 15 & 5.6 & 40 \\
\hline 1 & 5 & 2 & 17 & 6.5 & 45 \\
\hline 1 & 5 & 3 & 19 & 7.4 & 51 \\
\hline 1 & 5 & 4 & 22 & 8.3 & 57 \\
\hline 1 & 5 & 5 & 24 & 9.1 & 64 \\
\hline 2 & 0 & 0 & 4.5 & 1.1 & 18 \\
\hline 2 & 0 & 1 & 6.8 & 2.1 & 22 \\
\hline 2 & 0 & 2 & 9.1 & 3.1 & 27 \\
\hline 2 & 0 & 3 & 12 & 4.1 & 32 \\
\hline 2 & 0 & 4 & 14 & 5.2 & 37 \\
\hline 2 & 0 & 5 & 16 & 6.2 & 43 \\
\hline 2 & 1 & 0 & 6.8 & 2.1 & 22 \\
\hline 2 & 1 & 1 & 9.2 & 3.1 & 27 \\
\hline 2 & 1 & 2 & 12 & 4.2 & 32 \\
\hline 2 & 1 & 3 & 14 & 5.2 & 38 \\
\hline 2 & 1 & 4 & 17 & 6.3 & 44 \\
\hline 2 & 1 & 5 & 19 & 7.3 & 50 \\
\hline 2 & 2 & 0 & 9.3 & 3.2 & 27 \\
\hline 2 & 2 & 1 & 12 & 4.2 & 33 \\
\hline 2 & 2 & 2 & 14 & 5.3 & 38 \\
\hline 2 & 2 & 3 & 17 & 6.4 & 44 \\
\hline 2 & 2 & 4 & 19 & 7.4 & 51 \\
\hline 2 & 2 & 5 & 22 & 8.4 & 58 \\
\hline 2 & 3 & 0 & 12 & 4.3 & 33 \\
\hline 2 & 3 & 1 & 14 & 5.4 & 39 \\
\hline 2 & 3 & 2 & 17 & 6.5 & 45 \\
\hline 2 & 3 & 3 & 20 & 7.5 & 52 \\
\hline 2 & 3 & 4 & 22 & 8.5 & 59 \\
\hline 2 & 3 & 5 & 25 & 9.4 & 67 \\
\hline 2 & 4 & 0 & 15 & 5.5 & 39 \\
\hline 2 & 4 & 1 & 17 & 6.5 & 45 \\
\hline 2 & 4 & 2 & 20 & 7.6 & 52 \\
\hline 2 & 4 & 3 & 23 & 8.6 & 60 \\
\hline 2 & 4 & 4 & 25 & 9.5 & 68 \\
\hline 2 & 4 & 5 & 28 & 10 & 76 \\
\hline 2 & 5 & 0 & 17 & 6.6 & 46 \\
\hline 2 & 5 & 1 & 20 & 7.7 & 53 \\
\hline 2 & 5 & 2 & 23 & 8.7 & 60 \\
\hline 2 & 5 & 3 & 26 & 9.6 & 69 \\
\hline 2 & 5 & 4 & 29 & 11 & 78 \\
\hline 2 & 5 & 5 & 32 & 11 & 87 \\
\hline
\end{tabular}

\begin{tabular}{|c|c|c|c|c|c|}
\hline \multicolumn{3}{|c|}{ positive number } & \multicolumn{3}{|c|}{ MPN in $100 \mathrm{~mL} \&$ confidence limit } \\
\hline \multirow{2}{*}{$10 \mathrm{~mL}$} & \multirow{2}{*}{$1 \mathrm{~mL}$} & \multirow{2}{*}{$0.1 \mathrm{~mL}$} & \multirow{2}{*}{ MPN } & \multicolumn{2}{|c|}{$95 \%$ confidence limit } \\
\hline & & & & lower & upper \\
\hline 4 & 3 & 3 & 45 & 15 & 140 \\
\hline 4 & 3 & 4 & 52 & 17 & 160 \\
\hline 4 & 3 & 5 & 59 & 19 & 190 \\
\hline 4 & 4 & 0 & 34 & 12 & 94 \\
\hline 4 & 4 & 1 & 40 & 14 & 120 \\
\hline 4 & 4 & 2 & 47 & 15 & 140 \\
\hline 4 & 4 & 3 & 54 & 17 & 170 \\
\hline 4 & 4 & 4 & 61 & 20 & 190 \\
\hline 4 & 4 & 5 & 69 & 22 & 220 \\
\hline 4 & 5 & 0 & 41 & 14 & 120 \\
\hline 4 & 5 & 1 & 48 & 16 & 150 \\
\hline 4 & 5 & 2 & 56 & 18 & 180 \\
\hline 4 & 5 & 3 & 64 & 20 & 200 \\
\hline 4 & 5 & 4 & 72 & 23 & 220 \\
\hline 4 & 5 & 5 & 81 & 27 & 240 \\
\hline 5 & 0 & 0 & 23 & 8.8 & 61 \\
\hline 5 & 0 & 1 & 31 & 11 & 87 \\
\hline 5 & 0 & 2 & 43 & 14 & 130 \\
\hline 5 & 0 & 3 & 58 & 18 & 180 \\
\hline 5 & 0 & 4 & 76 & 25 & 230 \\
\hline 5 & 0 & 5 & 95 & 33 & 280 \\
\hline 5 & 1 & 0 & 33 & 12 & 92 \\
\hline 5 & 1 & 1 & 46 & 15 & 140 \\
\hline 5 & 1 & 2 & 63 & 20 & 200 \\
\hline 5 & 1 & 3 & 84 & 28 & 250 \\
\hline 5 & 1 & 4 & 110 & 37 & 300 \\
\hline 5 & 1 & 5 & 130 & 47 & 350 \\
\hline 5 & 2 & 0 & 49 & 16 & 150 \\
\hline 5 & 2 & 1 & 70 & 22 & 220 \\
\hline 5 & 2 & 2 & 94 & 32 & 280 \\
\hline 5 & 2 & 3 & 120 & 43 & 330 \\
\hline 5 & 2 & 4 & 150 & 55 & 400 \\
\hline 5 & 2 & 5 & 180 & 66 & 470 \\
\hline 5 & 3 & 0 & 79 & 26 & 240 \\
\hline 5 & 3 & 1 & 110 & 38 & 310 \\
\hline 5 & 3 & 2 & 140 & 52 & 380 \\
\hline 5 & 3 & 3 & 170 & 66 & 470 \\
\hline 5 & 3 & 4 & 210 & 80 & 560 \\
\hline 5 & 3 & 5 & 250 & 93 & 680 \\
\hline 5 & 4 & 0 & 130 & 47 & 360 \\
\hline 5 & 4 & 1 & 170 & 65 & 460 \\
\hline 5 & 4 & 2 & 220 & 83 & 590 \\
\hline 5 & 4 & 3 & 280 & 100 & 760 \\
\hline 5 & 4 & 4 & 350 & 120 & 1000 \\
\hline 5 & 4 & 5 & 430 & 140 & 1300 \\
\hline 5 & 5 & 0 & 240 & 89 & 640 \\
\hline 5 & 5 & 1 & 350 & 12 & 1000 \\
\hline 5 & 5 & 2 & 540 & 160 & 1800 \\
\hline 5 & 5 & 3 & 920 & 290 & 2900 \\
\hline 5 & 5 & 4 & 1600 & 540 & \\
\hline 5 & 5 & 5 & $\geq 2400$ & & \\
\hline
\end{tabular}

Note: The MPN calibration scale is based on the program developed in 1985 by Hurley \& Roscoe. This program makes provision for the reliability coefficient to evaluate the reliability of data. In case that the combination of positive number indicates <9, MPN may not be valid by some sort of error cause. MPN indicated in not bold area should be handled as a reference value because of $>9$. 
is equivalent to that of Japanese tap water. ${ }^{6}$ However, what is more important is that local residents have a good grasp of the level of well contamination in communities, and of the environment associated with various water resources; this has empowered residents to be proactive and to develop a sense of ownership as the decision makers. In order to actualize such water resource management of/for/by local citizens, it was essential that they could run water contamination tests themselves.

The quantitative evaluation of coliform bacteria and E. coli contamination has relied on colony counting by specialists; this means that the cost per sample is prohibitively high. However, previously developed simplified methods have not been widely adopted due to problems with reliability. This situation is beginning to change, as simplified and low-cost methods have recently been significantly improved in Japan ("low-cost" meaning not only testing cost but also samples transit and other related costs). Currently, the data quality obtained using the new simplified on-site method is comparable to that obtained in expert laboratories. With the help of the EC-B and the MPNP, we have been actively involving local people in monitoring the water environment and co-creating the opportunity for them to start thinking about the future of the water environment in their own communities.

\section{THE RESULTS OF FIELD SURVEYS}

We conducted four joint (Japanese researchers, Filipino researchers, and related local citizen members) surveys along with the concerned parties in the municipality of Angono. The results of the four surveys are summarized in Tables 3, 4, 5, and 6. All sampling sites information were provided by barangay offices in the municipality of Angono.

These joint surveys were conducted for the main purpose of technology transfer during these survey periods. They focused on voluntary surveys of well water in the town of Angono, as well as on local sales of bottled water. The outline of the survey and obtained results of the joint surveys are as follows:

At the first survey (March 14-21, 2014), comprehensive sampling surveys were performed at areas in which the well water was mainly used as the domestic water supply. This water source was heavily contaminated by E. coli (Table 3). This survey revealed that $\mathrm{E}$. coli concentration was generally high in "open type (uncovered)" wells, and lower in the "closed type (covered: major type of cover made from tin steel plate, concrete materials or woods)" counterparts. The running water in this area was sound in general. With regard to geographical features, elevated $\mathrm{E}$. coli concentrations were found in wells at higher altitude, such as in the mountainous area of Mahabang Parang (Figure 1).

Table 3. First collaborated fieldworks results: 14-21 March, 2014

\begin{tabular}{|c|c|c|c|c|c|c|c|}
\hline \multirow{2}{*}{ No. } & \multirow{2}{*}{ Barangay } & \multirow{2}{*}{$\begin{array}{c}\text { Water Source } \\
\text { (e.g. Poso, Balon, Manila Water) }\end{array}$} & \multicolumn{3}{|c|}{ MPN Plate } & \multirow{2}{*}{$\begin{array}{l}\text { Coliform } \\
(+/-)\end{array}$} & \multirow{2}{*}{$\begin{array}{c}\text { E. Coli } \\
\text { MPN/100ml }\end{array}$} \\
\hline & & & Big & Medium & Small & & \\
\hline$A W-S R-1$ & San Roque & Spring & 3 & 0 & 0 & $(+)$ & 7.8 \\
\hline$A W-S R-2$ & San Roque & Deepwell (Delivered) & 0 & 3 & 3 & $(+)$ & 11 \\
\hline$A W-S R-3$ & San Roque & Well & 5 & 5 & 0 & $(+)$ & 240 \\
\hline$A W-S R-4$ & San Roque & Piston Pump & 0 & 0 & 0 & $(+)$ & 0 \\
\hline$A W-S R-5$ & San Roque & Angono River & 5 & 5 & 5 & $(+)$ & $\geq 2,400$ \\
\hline$A W-S R-6$ & San Roque & Manila Water & 0 & 0 & 5 & $(+)$ & 9 \\
\hline$A W-S R-7$ & San Roque & Deepwell & 0 & 0 & 0 & $(-)$ & 0 \\
\hline$A W-S R-8$ & San Roque & Manila Water & 0 & 0 & 0 & $(-)$ & 0 \\
\hline AW-SI-1 & San Isidro & Piston Pump & 0 & 0 & 0 & $(+)$ & 0 \\
\hline AW-SI-2 & San Isidro & River & 5 & 5 & 5 & $(+)$ & $\geq 2,400$ \\
\hline AW-SI-3 & San Isidro & Spring/ Salolo & 0 & 0 & 0 & $(+)$ & 0 \\
\hline AW-SI-4 & San Isidro & Deepwell & 0 & 0 & 1 & $(+)$ & 1.8 \\
\hline AW-SI-5 & Kalayaan / San Isidro & Spring & 0 & 0 & 0 & $(+)$ & 0 \\
\hline AW-SI-6 & San Isidro & Piston Pump & 2 & 0 & 0 & $(+)$ & 4.5 \\
\hline AW-SV-1 & San Vicente & Lake & 5 & 5 & 4 & $(+)$ & 1,600 \\
\hline AW-SV-2 & San Vicente & Well & 5 & 5 & 4 & $(+)$ & 1,600 \\
\hline AW-SV-3 & San Vicente & Manila Water & 0 & 0 & 0 & $(-)$ & 0 \\
\hline AW-SV-4 & San Vicente & Deepwell & 0 & 0 & 0 & $(-)$ & 0 \\
\hline AW-SV-5 & San Vicente & Piston Pump & 0 & 0 & 0 & $(+)$ & 0 \\
\hline AW-SV-6 & San Vicente & Deepwell & 0 & 0 & 0 & $(-)$ & 0 \\
\hline$A W-K a-1$ & Kalayaan / San Isidro & Spring & 0 & 0 & 0 & $(+)$ & 0 \\
\hline AW-Ka-2 & Kalayaan & Manila Water & 0 & 0 & 0 & $(-)$ & 0 \\
\hline AW-Ka-3 & Kalayaan & Manila Water & 0 & 0 & 0 & $(-)$ & 0 \\
\hline AW-Ka-4 & Kalayaan & Manila Water & 0 & 0 & 0 & $(+)$ & 0 \\
\hline
\end{tabular}


Table 3. First collaborated fieldworks results: 14-21 March, 2014 (continued)

\begin{tabular}{|c|c|c|c|c|c|c|c|}
\hline \multirow{2}{*}{ No. } & \multirow{2}{*}{ Barangay } & \multirow{2}{*}{$\begin{array}{c}\text { Water Source } \\
\text { (e.g. Poso, Balon, Manila Water) }\end{array}$} & \multicolumn{3}{|c|}{ MPN Plate } & \multirow{2}{*}{$\begin{array}{l}\text { Coliform } \\
(+/-)\end{array}$} & \multirow{2}{*}{$\begin{array}{c}\text { E. Coli } \\
\text { MPN/100m }\end{array}$} \\
\hline & & & Big & Medium & Small & & \\
\hline AW-MP-1 & Mahabang Parang & Piston Pump/Spring & 5 & 5 & 0 & $(+)$ & 240 \\
\hline AW-MP-2 & Mahabang Parang & Well & 5 & 5 & 1 & $(+)$ & 350 \\
\hline AW-MP-3 & Mahabang Parang & Well & 5 & 5 & 3 & $(+)$ & 920 \\
\hline AW-MP-4 & Mahabang Parang & Well & 5 & 5 & 5 & $(+)$ & $\geq 2,400$ \\
\hline AW-MP-5 & Mahabang Parang & Well & 5 & 5 & 5 & $(+)$ & $\geq 2,400$ \\
\hline AW-MP-6 & Mahabang Parang & Spring & 5 & 5 & 2 & $(+)$ & 540 \\
\hline AW-MP-7 & Mahabang Parang & Deepwell & 3 & 5 & 0 & $(+)$ & 25 \\
\hline AW-MP-8 & Mahabang Parang & Manila Water & 0 & 0 & 0 & $(-)$ & 0 \\
\hline$A W-S P-1$ & San Pedro & Manila Water & 5 & 5 & 1 & $(+)$ & 350 \\
\hline$A W-S P-2$ & San Pedro & Aquaflow/ Deepwell & 0 & 0 & 0 & $(+)$ & 0 \\
\hline$A W-S P-3$ & San Pedro & Barangay Water System/ Deepwell & 0 & 0 & 0 & $(-)$ & 0 \\
\hline$A W-S P-4$ & San Pedro & Barangay Water System/ Deepwell & 0 & 0 & 0 & $(-)$ & 0 \\
\hline AW-SP-5 & San Pedro & Piston Pump & 3 & 1 & 0 & $(+)$ & 11 \\
\hline$A W-S P-6$ & San Pedro & Piston Pump & 0 & 0 & 0 & $(+)$ & 0 \\
\hline$A W-S P-7$ & San Pedro & Well & 5 & 5 & 4 & $(+)$ & 1,600 \\
\hline AW-SP-8 & San Pedro & Well & 2 & 1 & 2 & $(+)$ & 12 \\
\hline$A W-S N-1$ & Sto. Nino & Deepwell & 0 & 0 & 0 & $(-)$ & 0 \\
\hline$A W-S N-2$ & Sto. Nino & Manila Water & 0 & 0 & 0 & $(-)$ & 0 \\
\hline$A W-S N-3$ & Sto. Nino & Piston Pump & 0 & 0 & 0 & $(-)$ & 0 \\
\hline$A W-S N-4$ & Sto. Nino & Manila Water & 0 & 0 & 0 & $(+)$ & 0 \\
\hline AW-PI-1 & Pob. Itaas & Manila Water & 0 & 0 & 0 & $(+)$ & 0 \\
\hline AW-PI-2 & Pob. Itaas & Manila Water & 0 & 0 & 0 & $(-)$ & 0 \\
\hline$A W-B-1$ & Bagumbayan & Piston Pump/ Well & 3 & 1 & 0 & $(+)$ & 11 \\
\hline$A W-B-2$ & Bagumbayan & Piston Pump/ Well & 0 & 0 & 0 & $(+)$ & 0 \\
\hline$A W-B-3$ & Bagumbayan & Piston Pump & 0 & 0 & 0 & $(+)$ & 0 \\
\hline$A W-B-4$ & Bagumbayan & Manila Water & 0 & 0 & 0 & $(-)$ & 0 \\
\hline AW-PI-1 & Pob. Ibaba & Well & 2 & 2 & 2 & $(+)$ & 14 \\
\hline AW-PI-2 & Pob. Ibaba & Piston Pump/Well & 0 & 0 & 0 & $(-)$ & 0 \\
\hline AW-PI-3 & Pob. Ibaba & Manila Water & 0 & 0 & 0 & $(+)$ & 0 \\
\hline AW-PI-4 & Pob. Ibaba & Deep well & 0 & 0 & 0 & $(-)$ & 0 \\
\hline
\end{tabular}

10 Barangays, 54 Samples

Table 4. Second collaborated fieldworks results: 8-11 February, 2015

\begin{tabular}{|c|c|c|c|c|c|c|c|}
\hline \multirow{2}{*}{ No. } & \multirow{2}{*}{ Barangay } & \multirow{2}{*}{$\begin{array}{c}\text { Water Source } \\
\text { (e.g. Poso, Balon, Manila Water) }\end{array}$} & \multicolumn{3}{|c|}{ MPN Plate } & \multirow{2}{*}{$\begin{array}{l}\text { Coliform } \\
(+/-)\end{array}$} & \multirow{2}{*}{$\begin{array}{c}\text { E. Coli } \\
\text { MPN/100ml }\end{array}$} \\
\hline & & & Big & Medium & Small & & \\
\hline$A W-S R-3$ & San Roque & Well & 5 & 5 & 1 & $(+)$ & 350 \\
\hline$A W-S R-5$ & San Roque & Angono River & 5 & 5 & 5 & $(+)$ & 2,400 \\
\hline AW-SI-2 & San Isidro & River & 5 & 5 & 5 & $(+)$ & 2,400 \\
\hline AW-SI-7 & San Isidro & Well & 5 & 5 & 5 & $(+)$ & 2,400 \\
\hline$A W-S V-1$ & San Vicente & Lake & 5 & 5 & 5 & $(+)$ & 2,400 \\
\hline AW-SV-2 & San Vicente & Well & 5 & 5 & 5 & $(+)$ & 2,400 \\
\hline$A W-M P-1$ & Mahabang Parang & Piston Pump/Spring & 5 & 5 & 1 & $(+)$ & 350 \\
\hline AW-MP-2 & Mahabang Parang & Well & 5 & 4 & 5 & $(+)$ & 430 \\
\hline AW-MP-3 & Mahabang Parang & Well & 5 & 4 & 5 & $(+)$ & 430 \\
\hline AW-MP-4 & Mahabang Parang & Well & 4 & 5 & 5 & $(+)$ & 81 \\
\hline AW-MP-5 & Mahabang Parang & Well & \multicolumn{5}{|c|}{ Abandoned } \\
\hline$A W-M P-6$ & Mahabang Parang & Spring & 3 & 4 & 5 & $(+)$ & 40 \\
\hline AW-MP-9 & Mahabang Parang & Deep well & 5 & 4 & 1 & $(+)$ & 170 \\
\hline AW-MP-10 & Mahabang Parang & Well & 5 & 5 & 5 & $(+)$ & 2,400 \\
\hline$A W-S P-1$ & San Pedro & Manila Water & \multicolumn{5}{|c|}{ Closed } \\
\hline AW-SP-7 & San Pedro & Well & 5 & 5 & 5 & $(+)$ & 2,400 \\
\hline
\end{tabular}

7 Barangays, 23 Samples 
Table 5. Third collaborated fieldworks results: 8-12 October, 2015

\begin{tabular}{|c|c|c|c|c|c|c|c|c|}
\hline \multirow[b]{2}{*}{ No. } & \multirow[b]{2}{*}{ Barangay } & \multirow{2}{*}{$\begin{array}{l}\text { Water Source } \\
\text { (e.g. Poso, Balon, } \\
\text { Manila Water) }\end{array}$} & \multicolumn{3}{|c|}{ MPN Plate } & \multirow{2}{*}{$\begin{array}{l}\text { Coliform } \\
(+/-)\end{array}$} & \multirow{2}{*}{$\begin{array}{c}\text { E. Coli } \\
\text { MPN/100ml }\end{array}$} & \multirow{2}{*}{$\begin{array}{r}\text { TDS } \\
\text { (ppm) }\end{array}$} \\
\hline & & & Big & Medium & Small & & & \\
\hline$A W-S R-3$ & San Roque & Well & 4 & 1 & 0 & + & 17 & 222 \\
\hline$A W-S R-5$ & San Roque & Angono River & 5 & 4 & 5 & + & 430 & 145 \\
\hline AW-SR-RPTW1 & San Roque & Manila Water & 0 & 0 & 0 & - & 0 & 66 \\
\hline AW-SI-2 & San Isidro & Labahan River & 5 & 4 & 5 & + & 430 & 113 \\
\hline AW-SI-7 & San Isidro & Well & 4 & 4 & 5 & + & 69 & 320 \\
\hline AW-SI-RPTW2 & San Ishidro & Manila Water & 0 & 0 & 0 & - & 0 & 69 \\
\hline AW-SV-1 & San Vicente & Lake Water & 5 & 3 & 5 & + & 250 & 144 \\
\hline AW-SV-2 & San Vicente & Well & 4 & 4 & 3 & + & 54 & 564 \\
\hline AW-SV-RPTW3 & San Vicente & Manila Water & 0 & 0 & 0 & - & 0 & 59 \\
\hline AW-MP-1 & Mahabang Parang & Piston Pump/Spring & 5 & 5 & 3 & + & 920 & 60 \\
\hline AW-MP-2 & Mahabang Parang & Well & 5 & 5 & 5 & + & $\geq 2400$ & 87 \\
\hline AW-MP-3 & Mahabang Parang & Well & 5 & 4 & 0 & + & 130 & 130 \\
\hline AW-MP-4 & Mahabang Parang & Well & 5 & 5 & 2 & + & 540 & 175 \\
\hline AW-MP-5 & Mahabang Parang & Well & \multicolumn{6}{|c|}{ Abandoned } \\
\hline AW-MP-6 & Mahabang Parang & Spring & 5 & 5 & 5 & + & $\geq 2400$ & 251 \\
\hline AW-MP-9 & Mahabang Parang & Deepwell & 0 & 0 & 0 & + & 0 & 100 \\
\hline AW-MP-10 & Mahabang Parang & Well & 5 & 5 & 2 & + & 540 & 175 \\
\hline AW-MP-RPTW5 & Mahabang Parang & Manila Water & 0 & 0 & 0 & - & 0 & 65 \\
\hline$A W-S P-1$ & San Pedro & Manila Water & \multicolumn{6}{|c|}{ Cannnot make sampling } \\
\hline AW-SP-7 & San Pedro & Deep Well & 0 & 0 & 0 & + & 0 & 498 \\
\hline$A W-S P-3 r d A D 1$ & San Pedro & Well & 0 & 0 & 0 & - & 0 & 499 \\
\hline AW-SP-RPTW4 & San Pedro & Manila Water & 0 & 0 & 0 & - & 0 & 70 \\
\hline AW-SP-RPTW5 & San Pedro & Manila Water & 0 & 0 & 0 & - & 0 & 67 \\
\hline
\end{tabular}

5 Barangay, 17 Samples, 6 Manila Water sampling points and 4 local bottled water samples (Manila Water based portable water)

Table 6. Fourth collaborated fieldworks results: 13-14 February, 2017

\begin{tabular}{|c|c|c|c|c|c|c|c|c|c|c|}
\hline \multirow[b]{2}{*}{ No. } & \multirow[b]{2}{*}{ Barangay } & \multirow{2}{*}{$\begin{array}{l}\text { Water Source } \\
\text { (e.g. Poso, Balon, } \\
\text { Manila Water) }\end{array}$} & \multicolumn{3}{|c|}{ MPN Plate } & \multirow{2}{*}{$\begin{array}{l}\text { Coliform } \\
(+/-)\end{array}$} & \multirow{2}{*}{$\begin{array}{c}\text { E. Coli } \\
\text { MPN/100ml }\end{array}$} & \multirow{2}{*}{$\begin{array}{c}\text { TDS } \\
\text { (ppm) }\end{array}$} & \multirow[b]{2}{*}{ EC } & \multirow[b]{2}{*}{$\mathrm{PH}$} \\
\hline & & & Big & Medium & Small & & & & & \\
\hline$A W-S R-3$ & San Roque & Well & 2 & 0 & 0 & + & 4.5 & 262 & $0.68 \mathrm{mS} / \mathrm{cm}$ & 7 \\
\hline AW-SR-5 & San Roque & Angono River & 5 & 4 & 5 & + & 430 & 149 & $0.39 \mathrm{mS} / \mathrm{cm}$ & 8.7 \\
\hline AW-SR-4thAD5 & San Roque & Spring & 0 & 0 & 0 & + & 0 & 131 & $0.34 \mathrm{mS} / \mathrm{cm}$ & 7.1 \\
\hline AW-SI-2 & San Isidro & Labahan River & 5 & 5 & 4 & + & 1,600 & 112 & $0.25 \mathrm{mS} / \mathrm{cm}$ & 8.6 \\
\hline AW-SI-8 & San Isidro & Spring / River & 3 & 5 & 3 & + & 37 & 151 & $50 \mu \mathrm{s} / \mathrm{cm}$ & 8.3 \\
\hline$A W-S V-1$ & San Vicente & Lake Water & 5 & 5 & 2 & + & 540 & 254 & $0.68 \mathrm{mS} / \mathrm{cm}$ & 7.6 \\
\hline$A W-S V-2$ & San Vicente & Well & 5 & 3 & 0 & + & 79 & 630 & $1.65 \mathrm{mS} / \mathrm{cm}$ & 7.3 \\
\hline AW-MP-1 & Mahabang Parang & Piston Pump/Spring & 5 & 5 & 0 & + & 240 & 67 & $119 \mu \mathrm{S} / \mathrm{cm}$ & 6.5 \\
\hline AW-MP-2 & Mahabang Parang & Well & 5 & 5 & 5 & + & $\geq 2400$ & 90 & $0.19 \mathrm{mS} / \mathrm{cm}$ & 6.9 \\
\hline AW-MP-3 & Mahabang Parang & Well & 5 & 5 & 1 & + & 350 & 144 & $0.29 \mathrm{mS} / \mathrm{cm}$ & 6.7 \\
\hline AW-MP-4 & Mahabang Parang & Well & 5 & 5 & 5 & + & $\geq 2400$ & 296 & $0.63 \mathrm{mS} / \mathrm{cm}$ & 7.2 \\
\hline AW-MP-6 & Mahabang Parang & Spring & 5 & 5 & 2 & + & 540 & 179 & $0.43 \mathrm{mS} / \mathrm{cm}$ & 6.9 \\
\hline AW-MP-9 & Mahabang Parang & Deepwell & \multicolumn{8}{|c|}{ pump not available } \\
\hline AW-MP-10 & Mahabang Parang & Well & 5 & 5 & 4 & + & 1,600 & 306 & $0.71 \mathrm{mS} / \mathrm{cm}$ & 7 \\
\hline AW-MP-4thAD4 & Mahabang Parang & Motor Pump / Deep Well & 0 & 0 & 0 & $+(10 \mathrm{ml} \times 3)$ & 0 & 78 & $164 \mu \mathrm{s} / \mathrm{cm}$ & 6.8 \\
\hline AW-SP-7 & San Pedro & Deep Well & \multicolumn{8}{|c|}{ cannnot use } \\
\hline AW-SP-10 & San Pedro & Well & & & & - & 0 & 63 & $157 \mu \mathrm{s} / \mathrm{cm}$ & 8 \\
\hline AW-SP-11 & San Pedro & Well & 2 & 0 & 0 & + & 4.5 & 601 & $1.46 \mathrm{mS} / \mathrm{cm}$ & 7.6 \\
\hline AW-SP-12 & San Pedro & Well & 4 & 0 & 0 & + & 13 & 702 & $1.82 \mathrm{mS} / \mathrm{cm}$ & 7.6 \\
\hline$A W-S P-13$ & San Pedro & Deep Well & & & & - & 0 & 481 & $1.26 \mathrm{mS} / \mathrm{cm}$ & 7.6 \\
\hline AW-SP-14 & San Pedro & Well & 3 & 0 & 0 & + & 7.8 & 425 & $1.12 \mathrm{mS} / \mathrm{cm}$ & 7.7 \\
\hline$A W-B-4 t h A D 1$ & Bagumbayan & Piston Pump/ Well & 4 & 0 & 0 & + & 13 & 478 & $1.17 \mathrm{mS} / \mathrm{cm}$ & 7.5 \\
\hline$A W-B-4$ thAD2 & Bagumbayan & Piston Pump/ Well & 0 & 0 & 0 & $+(10 \mathrm{ml} \times 1)$ & 0 & 511 & $1.33 \mathrm{mS} / \mathrm{cm}$ & 7.5 \\
\hline$A W-B-4$ thAD3 & Bagumbayan & Piston Pump & & & & - & 0 & 457 & $1.19 \mathrm{mS} / \mathrm{cm}$ & 7.6 \\
\hline
\end{tabular}

6 Barangays, 22 Samples 
The second survey (February 8-15, 2015; Table 4), was conducted in the areas in which high E. coli concentrations were found, in order to narrow down to the areas that may constitute as index area. Taking the consultation with the mayor of Angono into consideration, we increased the number of samples taken at San Pedro and the surrounding areas. This led us to identify San Pedro as the index area. San Pedro directly faces Laguna de Bay, and therefore this barangay is prone to flood damage. During the process of narrowing down the index targets, we observed that the $\mathrm{E}$. coli count was generally higher in samples obtained from the mountainous area (Mahabang Parang) in comparison with those from the other areas (Table 4).

The results of the third (October 8-12, 2015; Table 5) and fourth surveys (February 13-14,2017; Table 6) suggested that there was a seasonal variation in E. coli count in the samples obtained from San Pedro. On the other hand, the E. coli count in Mahabang Parang was consistently high in each survey (Tables 5 and 6). Future surveys, which will include input from the local residents, are needed in order to identify contamination sources of $\mathrm{E}$. coli in the mountainous area.

In these surveys, we conducted the on-site quantitative evaluation of E. coli counts in a wide range of the target samples. This included water from shallow, deep and piston pump-type wells; spring water, tap water, and bottled tap water sold by the local bottled water shops; the Laguna de Bay's surface water; and river water. Below we summarize the results of these surveys.

First, we did not find any E. coli in tap water, and residual chlorine was at safe level, even when compared to that of the Japanese standards. Therefore, no changes in the treatment and handling of tap water were required. Second, the presence of E. coli in well water means that it should be boiled in a kettle and left to stand for at least 10 minutes before drinking, in order to allow settling of all fine incorporated material. This will significantly reduce the risk of infection, since coliform bacteria and E. coli are easily killed when a temperature of $75^{\circ} \mathrm{C}$ or higher is maintained for over 1 minute. We note that the boiling approach is difficult in cases where heavy metals are present. However, additional surveys we carried out indicated that there was no contamination due to heavy metals in the domestic water in the town of Angono. ${ }^{6,7}$ Third, changes of well water quality were significantly affected by introduction of litter and other foreign substances. Accordingly, we found in the tracking surveys that just covering the wells with a simple lid could significantly reduce the E. coli count.

\section{Community initiative action: Angono Safe Water Association Inc. (ASWAI)}

On the other hand, our research inspired local community efforts. Local citizens organized an NGO "Angono Safe Water Association Inc. (ASWAI)". This was achieved in cooperation with local scientists, regional medical engineers, and citizens. They serve as the check and balance, transparency monitors, and partners to maintain the delivery of safe water in the town of Angono.

ASWAI was organized on October 23, 2015 from the initiative of the Angono Municipal Health Office. This organization was spontaneously organized by Angono Municipal Health Office and local stakeholders. They organized the predecessor voluntary association "Angono Water Refilling Station Association (AWRSA)" in 2014. Also, they had a strategy based on re-activating the AWRSA as Non-Government Organization (NGO) member of the local Water Quality Council.

The Angono Municipal Health Office invited the Water Refilling Station owners and managers for stakeholders meeting on October 23, 2015 to report our collaborative research; discuss the proposed regulation and monitoring for water and food sanitation ordinance, regulation of prices, process in business permit and sanitary permit; and re-organize the local water quality council. The participants elected their officers and elected Ms. Josefina Bautista as the President of the water association. Mayor Calderon formally officiated the oath taking of water association officers on October 26, 2015. The water association pursued the registration with the Securities and Exchange Commission (SEC) Registration, under the name of Angono Safe Water Association Inc. (ASWAI), with SEC. Reg. CN201664244. From then to the present, the said partner of the Angono Municipal Health Office, maintains, monitors, and regulates the water quality in Angono, Rizal.

\section{CONCLUSION}

Quantification of coliform bacteria or E. coli derived from the feces is a well-established method for estimating water quality index. ${ }^{13}$ Although by no means a universal method, it is an effective procedure for reducing water-borne diseases such as typical diarrhea, which most often affects old people and young children. ${ }^{14}$ Consistent with the results of Moe et al. ${ }^{15}$ which demonstrate the association of fecalderived microbial properties in drinking water with diarrhea in the Philippines, our current results show that monitoring of E. coli is an important public health strategy. This is why it is important that local residents participate in the testing of water quality and in the decision-making process that accompanies water-related public health issues.

Following the transfer of a simple technology for water quality evaluation supported by the track records in Japan, our collaborative effort has demonstrated that E. coli represents one of the risk factors for bacterial infection upon exposure to domestic water. In addition, our efforts have led to the creation of ASWAI that will work for the citizens in the town of Angono in order to carry out the business of water quality assessment and certification. ${ }^{8}$

We suggest that the future conservation and sanitation of regional water environments can be safeguarded if local residents take the initiative to understand the regional 
water environment through monitoring E. coli. Conversely, the conservation of drinking water quality is challenging if the regional sanitary environment remains poor, or if a currently wealthy environment should become poorer. ${ }^{14} \mathrm{We}$ expect that the small but significant activities in the town of Angono will bring favorable ripple effects to many areas of the Philippines in the future.

\section{Acknowledgments}

We are grateful to the University of the Philippines Manila, Angono Municipal Office, and Angono Municipal Health Office for the great support provided to our collaborative activities in the field. Thank you to Nissui Pharmaceutical Co., Ltd. for the advice on the fluorescence reaction related to the EC-Blue100 and MPN-Plate results. We also appreciate Dr. Kiyoyuki Yaota's cooperation and the Research Institute for Humanity and Nature (RIHN), "Designing Local Frameworks for Integrated Water Resources Management" Project (C-09-Init) who supported the methodology establishment activities.

\section{Statement of Authorship}

Kato and Maruyama conceived the idea to evaluation of E.coli levels in daily life water. Kato, Maruyama, Merino, and Juban collected water samples and evaluate all samples in on-site. Kato, Maruyama and Merino processed analytical data, and wrote the paper. All authors approved the final version submitted.

\section{Author Disclosure}

All authors declared no conflicts of interest.

\section{Funding Source}

This study was partly supported by a Grant-in-Aid for Scientific Research to HK (15K00672, FY 2015-2017) and TH (A26247094, FY 2014-2019) from the Ministry of Education, Culture, Sports, Science and Technology, Japan.

\section{REFERENCES}

1. Fewtrell L, Bartram J. Water quality: guidelines, standards and health: assessment of risk and risk management for water-related infectious diseases. 2001. Geneva, World Health Organization (WHO).

2. WHO. Guidelines for drinking-water quality. 2011. 4th ed. Geneva, Switzerland: World Health Organization.
3. WHO. WHO Guidelines for the Safe Use of Wastewater, Excreta and Greywater. 2006. Geneva, Switzerland: World Health Organization.

4. WHO. Guidelines for Safe Recreational Water Environments: Swimming Pools and Similar Environments. 2006. Geneva, Switzerland: World Health Organization.

5. Urase T, Nadaoka K, Kusakabe O, Siringan F, Miyashita K and Suzuki Y. Comparative Study on Heavy Metals Contained in Leachates from Solid Waste Disposal Sites and in Road Deposits in Japan and in the Philippines. Journal of Japan Society on Water Environment, 2002; Vol.25, No.11: 657-60.

6. Maruyama S, Kato $\mathrm{H}$, Hirata $\mathrm{T}$, et al. Concentrations of trace elements in daily life water consumed in Angono, Republic of the Philippines. Acta Med Philipp. 2020; 54 (2): 167-74. DOI: https:// doi.org/10.47895/amp.v54i2.1507

7. Maruyama S, Kato H, Hirata T, et al. Concentrations of trace elements in bottled waters consumed in Republic of the Philippines. Acta Med Philipp. 2020; 54 (5): 525-30. DOI: https://doi.org/10.47895/ amp.v54i5.2239

8. Kato H, Maruyama S, J, Noel R. and M, Gilbert J (edited). A Small Book About Domestic Water in Angono, Rizal, Philippines: for Sharing Portable Water for all Local People. 2018. [cited 2021 Feb]. Version.2, Osaka, Japan: JSPS KAKENHI Grant Number 15K00672 Research Project, "Designing Collaborate Activities for Establishment "Local Water Quality Evaluation by Stakeholders" based on Simple Checking Methods". : https://www.researchgate.net/ publication/325391980_A_Small_Book_About_Domestic_Water_ in_Angono_Rizal_Philippines_for_Sharing_Potable_Water_for_ all_Local_People_JSPS_KAKENHI_Grant_Number_15K00672_ Research_Project_Designing_Collaborate_Activities_for_Es

9. Department of Environment and Natural Resources in Philippines (DENR). DENR Administrative Order No.34: 1990, Subject: Revised Water usage and classification/Water quality criteria amending section Nos.68 and 69, Chapter III of the 1978 NPCC rules and regulations.

10. Ministry of Health, Labour and Welfare (MHLW), Japan. Inspection method according to the water quality standards. 2003. [cited $2021 \mathrm{Feb}$ ]. MHLW announcement No.261, Tokyo, Japan. : http://www.mhlw.go. jp/file/06-Seisakujouhou-10900000-Kenkoukyoku/0000045881.pdf>

11. Ministry of Health, Labour and Welfare (MHLW), Japan. Inspection method according to the water quality standards. 2003. [cited 2021 Feb]. MHLW announcement No.261, Tokyo, Japan: MHLW. : http://www.mhlw.go.jp/file/06-Seisakujouhou-10900000Kenkoukyoku/0000045881.pdf

12. Ministry of Health, Labour and Welfare (MHLW), Japan. Laboratory procedure of the water quality management goal setting items.. 2018. [cited 2021 Feb]. Tokyo, Japan: MHLW. : http://www.mhlw.go.jp/ file/06-Seisakujouhou-10900000-Kenkoukyoku/0000102486.pdf

13. Nissui Pharmaceutical CO., LTD. EC Blue MPN Plate MPN Chart. 2009. Tokyo, Japan: Nissui Pharmaceutical CO., LTD.

14. VanDerslice J, Briscoe J. Environmental interventions in Developing Countries: Interactions and Their Implications. American Journal of Epidemiology, 1995; Vol.141, No.2: 135-44.

15. Moe CL, Sobsey MD, Samsa GP, Mesolo V. Bacterial indicators of risk of diarrhoeal disease from drinking-water in the Philippines. Bulletin of the World Health Organization, 1991; 69(3): 305-17. 